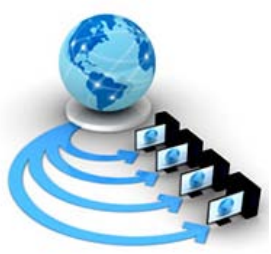

International Journal of Advanced Research in Computer Science

RESEARCH PAPER

\author{
Available Online at www.ijarcs.info
}

\title{
A STUDY ON INTELLECTUAL PROPERTY RIGHT AND DIGITAL WATERMARKING
}

\author{
Himanshu Rastogi \\ Research Scholar, \\ Mewar University, Chittorgarh, \\ Rajasthan (India)
}

\author{
Dr. B.K.Sharma \\ Professor, Department of MCA, \\ AKG Engineering College, \\ Ghaziabad (India)
}

\begin{abstract}
With the rapid growth of information technology, the importance of digitization has become increased. Today, everyone is sharing their original contents on the internet. It is necessary to protect such original/licensed content, so that unauthorized user can not access the original content and also not able to make fake copies of such original contents. Digital Watermarking technology is being adopted for the assurance of the data authentication and its protection of the digital content. Digital Watermarking has becomes one of the research area in many fields. This paper gives the brief introduction about India's participation in Intellectual Property Right and Digital Watermarking Techniques \& its applications.
\end{abstract}

Keywords: Intellectual Property Right, Copyright, Trademark, Patent, Digital Watermarking

\section{INTRODUCTION}

With the advent of the knowledge and information technology era, most of the Chief Information Officer (CIO) and Chief Technology Officer (CTO) are confident about the fact that the most of the business organization are using their business software in original form and their software are free from risks. While in a survey released by Business Software Alliance in 2013, it is found that 43 percent of the software installed on computers around the world was not properly licensed, which shows an increase of 42 percent in previous study. The result was commercial value slipped to $\$ 62.7$ billion [11].

Intellectual Property Right and Copyright are the solutions of such kind of activities. With the help of IPR, creativity can be encouraged for everyone. Protecting IP is also seen as a method of promoting creativity. If no one is allowed to copy another person's work without permission then piracy can be stop.

Copyright protection involves ownership authentication and can be used to identify illegal copies. One approach to copyrighting is to mark works by adding information about their relationship to the owner by a digital watermark. Digital watermarking provides a means of placing information within digital works. This information may be slightly changed or modified. Digital watermark could be visible or invisible. Digital watermarking has become an important research area.

\section{GLOBAL IPR PROTECTION AND INDIA'S PARTICIPATION}

\section{A. IPR Protection}

"Intellectual Policy" is defined as the tangible or intangible results of research, development, teaching, or other intellectual activity [1]. Intellectual property may include the following products:

\section{i. Patent}

Patent is defined as the legal right of an originator to keep out other persons from making or using a particular discovery. This right is called as 'Intellectual Property Right' and it can be viewed to encouragement of the originator for innovation.
In India, the law governing patents is the Patents Act, 1970 ("Patents Act"). In India's continued efforts to comply with it's commitment under TRIPS the Patents Act has been amended thrice since 1995, by the Patents (Amendment) Act, 1999 ("First Amendment”), the Patents (Amendment) Act, 2002 ("Second Amendment") and Patents (Amendment) Act, 2005 ("Third Amendment"), Prior to the Third Amendment, the President of India had promulgated Patents (Amendment) Ordinance, 2004 ("Ordinance”), which was later replaced by the Third Amendment.44 The legislation is supported by the Patents Rule, 2003 ("Rules")[8].

\section{ii. Trademark}

A trademark is used to identify and distinguishes the source of the products of one party from those of others, it could be in any form like word, name or symbol.

In India, trademarks are protected both under statutory law and common law. The Trade and Merchandise Marks Act, 1940 ("TM Act, 1940") was the first law in this regard in India, which was replaced later by the TM Act, 1958. The Trade Marks Act, 1999 ("TM Act") - which has replaced the TM Act, 1958 - came into effect on September 15, 2003 and is in compliance with the TRIPS obligations. The TM Act allows for the registration of service marks and threedimensional marks as well. India follows the NICE Classification of goods and services, which is incorporated in the Schedule to the Rules under the TM Act.1 A Trade Marks Registry had been established for the purposes of the TM Act, 1940, which has continued to function under the TM Act, 1958 and TM Act. The Trade Marks Registry is under the charge of the Registrar of Trademarks. The head office of the Trade Marks Registry is in Bombay (Mumbai) and its branches are at Calcutta (Kolkata), Delhi, Madras (Chennai), and Ahmedabad. The territorial jurisdiction of each office has also been allocated [8].

iii. Copy Right

Copyright is a set of exclusive rights granted by the Government to protect the particular form, way or manner in which information or concepts are expressed [10]. Copyright is administered and enforced domestically, and 
while there is a great deal of harmonization between countries it is important to check the laws in the country (or countries) in which you wish to protect your copyright. Copyright does not protect the information but the original form of expression. It protects the further copying of that form of expression. Copyright protection is generally "works" or "other subject matter".

The Copyright Act, 1957 (“Copyright Act”), supported by the Copyright Rules, 1958 ("Copyright Rules"), is the governing law for copyright protection in India. Substantial amendments were carried out to the Copyright Act, in early 2012 (“Amendment”).

The Copyright Act provides that a copyright subsists in an original literary, dramatic, musical or artistic work, cinematograph films, and sound recordings. However, no copyright subsists in a cinematograph film if a substantial part of the film is an infringement of the copyright in any other work or in a sound recording, if in making the sound recording of a literary, dramatic or musical work, copyright in such work is infringed. A computer programme is treated as a "literary work" and is protected as such [8].

\section{B. India's Participation}

According to the article published in TheHindu.com, titled "Intellectual Property index India remains near bottom", dated 09/02/2017, India remains near the bottom in an international Intellectual Property (IP) index by being ranked 43rd out of 45 countries, shown in figure (1), according to a report by the U.S. Chamber of Commerce's Global Intellectual Property Center (GIPC).

The report said it includes $90 \%$ of global gross domestic product, and grades countries on patents, trademarks, copyright, trade secrets, enforcement, and international treaties. Only two countries were ranked below India - Pakistan (44th) and Venezuela (45th).

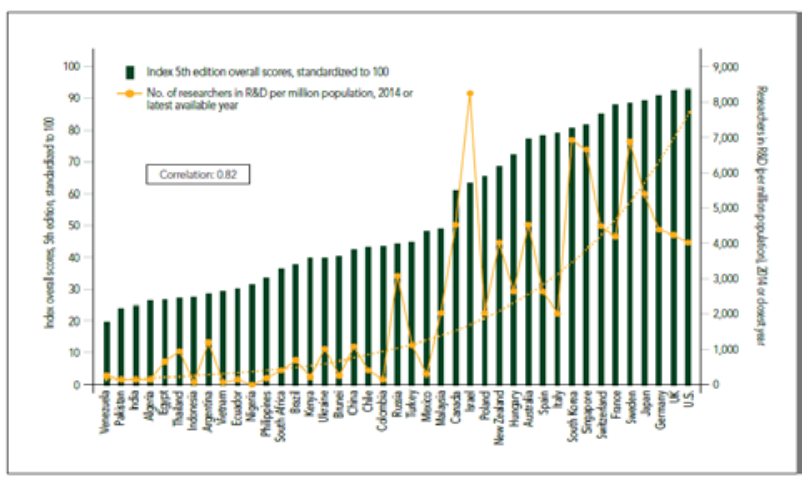

Sources: World Bank (2016)4; GIPC (2017)

Figure: (1) - Report by the U.S. Chamber of Commerce’s GIPC

The report added, "While the Indian government issued the National Intellectual Property Rights (IPR) Policy in 2016, IPintensive industries continued to face challenges in the Indian market with regard to the scope of patentability for computerimplemented inventions, Section 3(d) of the Indian Patent Act (that prevents ever-greening of patents), and the recent High Court of Delhi decision regarding photocopying copyrighted content."

The report said, India's key areas of weakness includes that "overall, National IPR Policy does not address fundamental weaknesses in India's IP framework, limited framework for protection of life sciences IP, patentability requirements being outside international standards, lengthy pre-grant opposition proceedings in place, and the 2016 High Court ruling on copyright infringement in the University of Delhi copy-shop case continuing to weaken the enforcement environment for rights holders.” It added that another of India’s weaknesses was also that it had "previously used compulsory licensing for commercial and nonemergency situations, (as well as India's) limited participation in international IP treaties.”

The report said its key findings included that a number of countries introduced new enforcement mechanisms and specialized IP courts to better combat counterfeiting and piracy. Besides, free trade agreements signed in 2016 helped raise the bar for protection of life sciences IP, copyrighted content online, and enforcement against IP theft, it said.

"Various governments undertook a review of their IP laws, recognizing that IP laws must keep pace with the emerging challenges IP owners face. Economies leveraged international partnerships through Patent Prosecution Highways,” it said, adding that despite these positive developments, some countries took steps to restrict IP rights in 2016. Also, countries introduced new requirements for local production, procurement, and manufacturing.

The report further said, "A number of governments attempted to limit the scope of patentability via both judicial decisions and legislation. Both individual governments and representatives of the multilateral institutions encouraged public officials to utilize compulsory licenses and expand exceptions and limitations in the name of increasing access." [9].

\section{DIGITAL WATERMARKING}

Digital watermarking is the embedding or hiding of information within a digital file without noticeably altering the file itself. Now digital image watermarking is increasing attention due to the fast developing in the internet traffic. Digital watermarking achieved is popularity due to its significance in content authentication and copyright protection for digital multimedia data. It is inserted invisible in host image so that it can be extracted at later times for the evidence of rightful ownership [2]. Through Java Programming Language, browsers based applications are now being protected using copyright protection schemes [3]. For embedding, the algorithm allows to add watermark signal into the original image to convert it into watermarked image, that watermark should be unique to the owner for the protection of their products from unauthorized copying. If the person, who receives the watermarked image, does not make any modification, the watermark is still present and it can be retrieved. The private or public key is used to secure during the embedding [15].

\section{A. Digital Watermarking Techniques}

Two main categories of Digital Watermarking Techniques are as shown in figure (2):

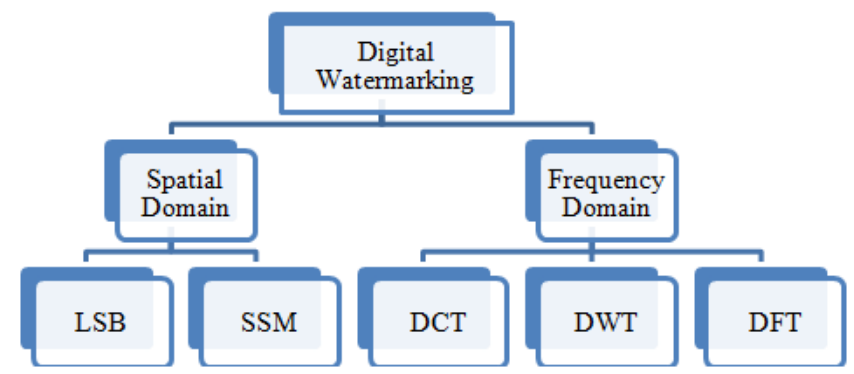

Figure: (2) - Types of Digital Watermarking Techniques

\section{i. Spatial Domain}

In this technique two or more subsets of an image are selected randomly and then pixels of the selected parts are 
modified. These converted subsets will then embed to the original images. Few algorithms based on this technique are Least Significant Bit (LSB) and SM modulation technique [4].

\section{a. Least Significant Bit (LSB)}

This is a simple method for the modification of pixels of an image. In this method, pixels will be selected from the lowest order bit of each pixel. For that, the last bit is checked to update for the modification. This may degrade the quality of the image and it depends on the length of the used lower bit of the pixels. In case modified or watermark image is cropped, the required message can be received by the receiver.

\section{b. SS Modulation Based Techniques}

The objective of SS modulation techniques is to distribute data over a large frequency band. It is used to hide or spread additional information across the frequency spectrum of the signal. This additional information is small pseudo noise across the signal, which is modulated by the embedded watermark [2].

\section{ii. Frequency Domain}

In this technique value of certain frequencies are modified from their original form. Several methods, such as Discrete Cosine Transform (DCT), Discrete Wavelet Transform (DWT) and Discrete Fourier Transform (DFT) are used to modify domain methods.

\section{a) The Discrete Cosine Transform (DCT):}

This is widely used technique for watermarking in still digital images. This represents the whole images as a coefficient of different frequencies of cosines, which is calculated by taking images size of $8 \times 8$ Block. Each block will then transform separately. In two dimensional DCT of an image, top left corner will represent lowest frequency coefficient, while bottom right corner will represent the highest frequency coefficient [4][7].

\section{b) Discrete Wavelet Transformation (DWT)}

For digital image processing and compression, it is a modern technique for watermarking. This kind of transform, provide the time frequency representation of a signal. This transformation is based on small wave having different frequencies. This small wave transform, decompose an image into 3 directions, horizontal, vertical, and diagonal. 2D transform can be completed by two separate one dimensional transforms [5][6].

\section{c) Discrete Fourier Transform (DFT):}

DFT transforms a continuous function into its frequency components. These transformations are more robust than spatial domain techniques. It hides the watermark information in noisy reason instead of smooth reason [12][13]. In digital image processing the even functions that are not periodic are defined as the integral of sine and cosine multiplied by a weighing function. This weighing function makes up the coefficients of the Fourier Transform of signal. In its frequency domain, it allows analysis and processing of signal by means of analyzing and updating these coefficients [14][4].

\section{B. Digital Watermarking Applications}

Digital Watermarks are potentially useful in many applications, including:

\section{i. Broadcast Monitoring}

Advertisement is a medium by which product promotion can be made through broadcasting. Advertising company wants to utilize all the allocated time, as per the contract signed with the broadcasters. Broadcasters should be aware of all the advertisements to be displayed as per contract. In this case a watermark can be embedded in advertisements for verification. This may affect the quality of the advertisement, but companies are using to monitor and to protect their broadcast.

\section{ii. Ownership Identification}

For proving the ownership of a document or item, owner identification can be printed on somewhere on the document or item. If mark is placed at the corner of the document, it can be removed by cropping the image. In this case Digital Watermarking helps to embed bit pattern in any part of the content.

\section{iii. $\quad$ Fingerprinting}

To trace the illegal copies, Digital Watermarking may be used. In fingerprinting, a unique bit sequence can be embedded, which can further be identified by the watermark detector. With this way licensed copies of the document or item can be protected.

\section{iv. Data Authentication}

Authentication of a licensed document or item can be provided by the watermarking. To maintain the originality of the image on the document or item a watermark, which could be of any type like a signature few keywords etc. may be embedded in the image. If someone changed or corrupt that image, it can be easily identified due to change in bit pattern.

\section{v. Copy Control}

This is used to prevent users from making unlicensed copies of the licensed document or item. Owner can introduce a digital watermark to identify original document or item. Unlicensed copies can easily be identified. A watermark can restrict a user to copy within a limit. After that limit user can never be able to copy that document.

\section{CONCLUSION}

This research paper presented the Global IPR protection and also the participation of India in this context. This paper also presented about trademark, patent, copyright. For the protection of IPR through Digital Watermarking, various digital watermarking techniques have been included in this research paper.

\section{ACKNOWLEDGMENT}

I am thankful to Professor (Dr.) B.K.Sharma, Department of MCA for encouragement, providing necessary guidance to prepare this paper and also to increase my knowledge. 


\section{REFERENCES}

[1] Ritu Rawat, Nikita Kaushik, Soumya Tiwari, “Digital Watermarking Techniques”, International Journal of Advanced Research in Computer and Communication Engineering, Vol. 5, Issue 4, ISSN (Online) 2278-1021 ISSN (Print) 2319 5940, (2016), 491-495

[2] J. K. Ravan, T.C.Thanuja "Watermarking Technique for security", International Conference on Recent Innovations in Engineering and Management, ISBN-978-81932074-5-1, (2016), 721-725

[3] Yogesh Awasthi, R.P.Agarwal, B.K. Sharma, "Intellectual Property Right Protection of Browser based Software through Watermarking Technique”, International Journal of Computer Application(IJCA), Volume 97- No.12, (2014), 32-36

[4] Monika Patel, Priti Srinivas Sajja, Ravi K. Sheth, "Analysis and Survey of Digital Watermarking Techniques", International Journal of Advanced Research in Computer Science and Software Engineering 3(10), (2013), 203-210

[5] Vidyasagar M. Potdar, Song Han, Elizabeth Chang, "A Survey of Digital Image Watermarking Techniques”, IEEE, (2005), 07803-9094.

[6] Ioannis Retsas, "A DCT - Based Image Watermarking Algorithm Robust to Cropping and Compression”, MS Thesis, Naval Postgraduate School Monterey, California, (2002).
[7] Pereira S., Pun T., "Robust Template Matching for Affine Resistant Image Watermarks", IEEE Transactions on Image Processing, vol. 9, no. 6, (2000), 1123-1129.

[8] Nishith Desai Associates, Intellectual Property Law in India, July (2015)

[9] http://www.thehindu.com/business/Economy/IntellectualProperty-index-India-remains-near-bottom/article17277994.ece

[10] Factsheet, "What is Copyright", Australian Centre for Intellectual Property in Agriculture

[11] The Compliance Gap., BSA Global Software Survey, (2014)

[12] R. V. Totla, and K. S. Bapat, "Comparative Analysis of Watermarking in Digital Images using DCT and DWT", International Journal of Scientific and Research Publications, (2013), Vol. 3, Issue 2.

[13] Er. Sandeep Kaur, Er. Jaspreet Kaur, Er. Inderpreet Kaur, "Technicalities of Digital Watermarking: A Review", International Research Journal of Engineering and Technology (IRJET) e-ISSN: 2395 -0056 Volume: 03 Issue: 02, (2016) pISSN: 2395-0072.

[14] Ioannis Retsas, "A DCT - Based Image Watermarking Algorithm Robust to Cropping and Compression”, MS Thesis, Naval Postgraduate School Monterey, California, (2002).

[15] http://eprints.uthm.edu.my/6936/1/MOHAMED_ABDISALAN_ SAID.pdf 